\title{
Case - A tale of two boys: An atypical cause of pubertal precocity
}

Kosalan Akilan, $\mathrm{MD}^{1}$; Karmon Janssen, $\mathrm{DO}^{2}$; Armando Lorenzo, MD ${ }^{1}$; Fadi Zu'bi, MD ${ }^{1}$; Hal Scherz, MD²; Martin Koyle, $\mathrm{MD}^{1}$

${ }^{1}$ Sickkids, University of Toronto, Toronto, ON, Canada; ${ }^{2}$ Children's Healthcare of Atlanta and Emory University, Atlanta, GA, United States

Cite as: Can Urol Assoc J 2020 February 4; Epub ahead of print. http://dx.doi.org/10.5489/cuaj.6270

Published online February 4, 2020

$* * *$

\section{Introduction}

Testicular tumors are fairly uncommon in the prepubertal pediatric population, with solid tumors accounting for $1-2 \%$ of overall cases. ${ }^{1,2}$ Over the past 2 decades, it is now well accepted that majority of prepubertal pediatric testes tumors are benign. ${ }^{3}$ This has resulted in differing approaches in the diagnosis and management of testicular masses in such patients compared to historic paradigms. ${ }^{3}$

Leydig Cell Tumors (LCT) are neoplastic interstitial neoplasms of the testicle accounting for 1$3 \%$ of all testicular tumors in adults and $4-9 \%$ in prepubertal children. ${ }^{4,5}$ Herein, we report 3 patients presenting to our institutions, with LCT, including a 5-year old boy with a most unusual case of multifocal, bilateral LCT.

\section{Case report}

\section{Patient 1}

A 5-year 7-month old previously healthy boy presented with a 9-month history of behavioral changes and sleep disturbances. This was associated with a growth spurt along with recent pubic hair growth and penile enlargement (Fig 1A). Physical examination yielded an enlarged penis, scant coarse scrotal hairs with right-sided testicular mass with a volume of 5-6 mL.

Investigations revealed normal LH $(<0.4 \mathrm{IU} / \mathrm{L}), \mathrm{FSH}(<0.4 \mathrm{IU} / \mathrm{L})$, androstenedione $(1.1$ nmol/L), 17-OHP (0.7 nmol/L), AFP ( $2 \mathrm{mcg} / \mathrm{L}), \beta-H C G(<1 \mathrm{IU} / \mathrm{L})$ and LDH $(582 \mathrm{IU} / \mathrm{L})$. There was an elevated serum testosterone $(5.6 \mathrm{nmol} / \mathrm{L})$ (Table 1.). Testicular ultrasound examination found right-sided unilateral testicular mass measuring 6x6×7 mm (Fig 2A). This patient had an accelerated bone age of 8 years \pm 18 months. Hormonal profile and tumor markers prompted partial orchiectomy, with subsequent pathology confirming the diagnosis of LCT (Fig 3A). He was followed for 5 months post-operatively until he was lost to follow up. 


\section{Patient 2}

A 5-year-old previously healthy boy presented with 1-year history of pubic and facial hair, acne, growth spurt and penile enlargement (Fig 1B). Testicular volumes were $5 \mathrm{~mL}$ (left) and $6 \mathrm{~mL}$ (right). The penile enlargement and pubic hair growth corresponded to Tanner Stage 3. Investigations revealed normal LH ( $<0.1 \mathrm{IU} / \mathrm{L}), \mathrm{FSH}(<0.1 \mathrm{IU} / \mathrm{L}), \mathrm{AFP}(3 \mathrm{mcg} / \mathrm{L}), \beta-\mathrm{HCG}(<1$ $\mathrm{IU} / \mathrm{L})$ and LDH (571 IU/L). The bloodwork revealed, however, elevated testosterone $(10.2$ $\mathrm{nmol} / \mathrm{L})$, androstenedione $(18.9 \mathrm{nmol} / \mathrm{L})$ and 17-OHP (4.3 nmol/L) (Table 1). Ultrasound demonstrated a large mass $(15 \times 14 \times 10 \mathrm{~mm})$ in the right testicle (Fig $2 \mathrm{~B})$ and 3 masses $(5 \times 5 \times 3$ $\mathrm{mm}, 6 \times 6 \mathrm{~mm}, 2 \mathrm{~mm}$ ) in the left testicle (Fig 2C). This patient also had an accelerated bone age of 13 years 6 months \pm 18.6 months. Bilateral exploration was carried out. Intraoperative ultrasound was used to assure all masses were removed. Pathology confirmed diagnosis of LCT, subsequent to testis sparing surgery involving bilateral partial orchiectomy (Fig 3B). He has been followed for $>5$ years with no recurrence. Leuprolide administration was ceased on his $11^{\text {th }}$ birthday. Genetic testing was carried out for DICER1 in both cases and was negative. The second patient subsequently developed central precocious puberty after LCT resection. This required gonadotropin-releasing hormone $(\mathrm{GnRH})$ treatment.

\section{Patient 3}

A 10-year-old male who initially presented to his endocrinologist at age of 6, with signs of early puberty, including: testosterone $(3.6 \mathrm{nmol} / \mathrm{L})$, mildly accelerated linear growth and pubic hair. Laboratory studies were all normal in this patient $17-\mathrm{OHP}(2.1 \mathrm{ng} / \mathrm{dL})$ and DHA-S (4.5 micromol/L). This was presumed central in origin and initial management included androgen suppression for three years by an endocrinologist whereby testosterone levels rose despite androgen suppression. Physical characteristics were consistent with advanced bone growth, pubic hair, penile enlargement and a finger-like scrotal structure (Fig 1C/D). An MRI of the brain was negative, however, a scrotal ultrasound identified bilateral, multifocal hyperechoic testicular masses, with the largest measuring 10x9mm on the left and four additional smaller hyperechoic masses on the right (Fig 2D/E). He was referred to urology for evaluation and management. Serum tumor markers were negative, including AFP (4.5 nmol/L), $\beta$-HCG $(<1$ $\mathrm{IU} / \mathrm{mL}$ ) and LDH (267 IU/L). He underwent bilateral enucleation of testicular masses. The right testicular multifocal masses were approached via an inguinal incision and the specimen were sent as frozen and confirmed to be LCT. The left testicular mass was removed via a scrotal approach (Fig 3C) The finger-like structure was excised circumferentially (Fig 4) and was identified as superficial angiomyxoma. He is currently only one month out from surgery and recovering well.

\section{Discussion}

LCT are the most common variation of sex cord stromal tumors, but overall, a rare testicular tumor subtype. ${ }^{6}$ As sex cord stromal tumors, LCT can manifest in the spermatic cords, adrenal 
glands and ovaries apart from the testicles. These tumors grow within the interstitium between seminiferous tubules and there are few reports of them in the literature. ${ }^{5}$ They are witnessed in the population in a bimodal age distribution occurring between 5-10 and 30-35 years of age. ${ }^{2}$ LCTs are typically functionally active, secreting testosterone causing precocious puberty. LCT are typically benign with only $10 \%$ of cases being potentially malignant. ${ }^{7}$ The etiology underlying LCT is not conclusive although there is incidence in patients with cryptorchidism and Klinefelter syndrome, with no association proven. ${ }^{8}$ DICER 1 encodes for RNase III endoribonuclease involved in microRNA production that have tumor suppressors and oncogenic roles, therefore associated with increased tumor development risk. ${ }^{9}$ DICER 1 mutations are screened in the work-up of Sertoli-Leydig malignancies along with other neoplasms, including: Wilms tumor, thyroid cysts and pleuropulmonary blastomas. ${ }^{10}$

Patients with an LCT usually present with virilization but sometimes can present with feminization (i.e. gynecomastia), superimposed on virilization symptoms. The precocial pubertal presentation can involve penile enlargement and pubic/facial hair growth seen in the cases described here. LCT tend to present as enlarged painless testicles causing discomfort due to swelling. ${ }^{11}$ Serology is valuable in differentiating origination of various testicular tumors. AFP is generally elevated in yolk sac tumors, a malignant testicular tumor, and should be within normal range in LCT. ${ }^{11}$ Elevations in testosterone is useful in demonstrating presence of LCT. Ultrasound examination is utilized in LCT diagnosis and aids in differentiating extratesticular diseases, including: epididymal cysts. ${ }^{11}$ These tumors have been characterized as well circumscribed hypervascularized hypoechoic lesions, less than $10 \mathrm{~mm}$ in diameter, without internal calcifications although there is variation reported in the literature. ${ }^{8,12}$ Confirmative diagnosis of LCT depends on histologic and immunohistochemical evaluation. ${ }^{8}$ Microscopically, cells are irregularly set in a sheet-like arrangement. ${ }^{5,8}$ Reinke crystals are pale staining inclusions that are pathognomonic for LCT but only found in $30-35 \%$ of patients. ${ }^{8,13}$

Testicular LCT traditionally were managed with radical inguinal orchiectomy. However, the majority of tumors have been found to be benign and radical orchiectomy might be considered over-treatment. In turn, LCTs that had favorable pathology or were benign were treated via conservative testes-sparing procedures whereby tumor enucleation is completed. ${ }^{13}, 14$ This approach to treatment has preserved testicle functionality preserving fertility in these patients. ${ }^{6}$ Observation is thought to be sufficient post-operatively to manage patients with benign LCT. ${ }^{13}$ Malignant LCT is generally managed with radical inguinal orchiectomy with retroperitoneal lymph node dissection (RPLND) for patients with unfavorable prognostic indicators (i.e. older, unfavorable pathology). ${ }^{7}$ Long term follow up of these patients suggests that this approach does not compromise oncological outcomes. ${ }^{6}$

Our first case demonstrates the classic presentation of an LCT in a pediatric patient with precocious puberty due to a unilateral and unifocal lesion. The second and third cases, however, are unusual and a rare presentation of LCT with not only bilateral LCT, but multifocality. LCT 
traditionally presents as unilateral and benign with an estimated 3-10\% appearing as bilateral, in adult series of patients. ${ }^{4,15}$ There are no prior cases found in the literature describing the presentation of a multifocal and bilateral LCT as seen with our patients. It is important to understand this unique presentation as Leydig Cell Hyperplasia $(\mathrm{LCH})$ would present in a multifocal manner and is difficult to differentiate from LCT. ${ }^{5}$ Both cases, however, presented with testosterone elevations and ultrasound findings of lesions less than $10 \mathrm{~mm}$. Both cases were managed with a testis sparing approach. Parenchyma preservation surgery is pursued to maximally preserve fertility, whereby radical orchiectomy is reserved for malignant or atrophic cases. $^{2,15}$

Central precocious puberty developed after tumor resection in our second case as previously shown in the literature. ${ }^{3,16}$ The mechanism is unknown but is theorized due to early maturation of the hypothalamic-pituitary-gonadal (HPG) axis from premature exposure of elevated testosterone via the LCT. ${ }^{3,16} \mathrm{GnRH}$ analogues are utilized in treatment of persistent central precocious puberty, suppressing the hypothalamus-pituitary-gonadal axis. ${ }^{3}$ Angiomyxomas have been associated with large cell calcifying Sertoli cell tumors, adrenocortical rests, and Leydig cell tumors found within patients diagnosed with Carney complex. ${ }^{17}$ Carney complex is an autosomal dominant syndrome first reported in 1985, and is associated with spotty pigmentation of the skin, endocrinopathy, and endocrine and nonendocrine tumors. ${ }^{18}$ These testicular tumors have been reported in the literature to arise as both bilateral and multifocal. ${ }^{19}$ The third patient has no family history of Carney complex or other clinical manifestations to support the diagnosis.

\section{Conclusion}

LCT may not always present as localized unilateral testicular masses as evidenced by this bilateral multifocal presentation. LCT is a rare occurrence and should be considered within the differential diagnosis in boys presenting with precocious or early puberty. This demonstrates use of testis sparing surgery as an approach to managing LCT to spare fertility. Many clinical principles should be taken away from this case series to include central precocious puberty can develop after LCT treatment in a patient with precocious puberty and that there are rare, yet clinically significant genetic syndromes that may manifest in pediatric testicular tumors. 


\section{References}

1. Carr MC, Snyder HM. Pediatric Oncology. In: Penn Clinical Manual of Urology 2007:853-75.

2. Akman H, Ege G, Yildiz S, et al. Incidental bilateral Leydig cell tumor of the testes. Urol Int 2003;71:316-18.

3. Verrotti A, Penta L, Zenzeri L, et al. True precocious puberty following treatment of a Leydig cell tumor: two case reports and literature review. Front Pediatr 2015;3:1-5.

4. Gheorghisan-Galateanu AA. Leydig cell tumors of the testis: a case report. BMC Res Notes 2014;7:1-6.

5. Mennie N, King SK, Marulaiah M, et al. Leydig cell hyperplasia in children: case series and review. J Pediatr Urol 2017;13:158-63.

6. Bozzini G, Picozzi S, Gadda F, et al. Long-term follow-up using testicle-sparing surgery for Leydig cell tumor. CLGC 2013;11:321-4.

7. Di F, Matteo I, Belmonte P. Lessons from 52 patients with Leydig cell tumor of the testis: the GUONE (North-Eastern Uro-Oncological Group, Italy) experience. Urol Int 2009;82:152-7.

8. Tsitouridis I, Maskalidis C, Panagiotidou D, et al. Eleven patients with testicular leydig cell tumors: clinical, imaging, and pathologic correlation. J Ultrasound Med 2014;33:1855-64.

9. Kock L De, Terzic T, Mccluggage WG, et al. DICER1 mutations are consistently present in moderately and poorly differentiated Sertoli-Leydig cell tumors. 2017;41:1178-87.

10. Lashkari HP, Nash R, Albanese A, et al. Treatment of high risk Sertoli-Leydig cell tumors of the ovary using a gonadotropin releasing hormone $(\mathrm{GnRH})$ analog. Pediatr Blood Cancer 2013;60:16-8.

11. Ross JH, Kay R. Prepubertal testis tumors. Rev Urol 2004;6:11-8.

12. Maxwell F, Izard V, Ferlicot $\mathrm{S}$, et al. Colour doppler and ultrasound characteristics of testicular Leydig cell tumours. Br J Radiol 2016:89

13. Sönmez N, Ton Ö, Arisan S, et al. Bilateral Leydig cell tumor of the testis: a case report. Contemp Oncol 2012;16:356-9.

14. Zu'bi F, Koyle M, Rickard M, et al. Testi-sparing surgery for pediatric leydig cell tumors: evidence of favorable outcomes irrespective of surgical margins. Pediatric Urology 2019;00:1-6.

15. Praz V, Strebel R, Regusci S, et al. Metachronous bilateral Leydig cell tumor in a male adult aged 20. Urol Int 2003;73:370-3.

16. Pozza C, Pofi R, et al. Clinical presentation, management and follow-up of 83 patients with Leydig cell tumors of the testis: a prospective case-cohort study. Hum Reprod 2019; 34:1389-1403.

17. Gourgari E, Saloustros E, Stratakis C. Large-cell calcifying Sertoli cell tumors of the testes in pediatrics. Curr Opin Pediatr 2012;24:518-522.

18. Carney J, Gordon H, et al. The complex of myxomas, spotty pigmentation, and endocrine overactivity. Medicine (Baltimore) 1985; 64:270-83. 
19. Lai J, Lee C, et al. Isolated large cell calcifying Sertoli cell tumor in a young boy, not associated with Peutz-Jehgers Syndrome or Carney complex. Ann Clin Lab Res 2015;3(1):2.

Figure and Tables

\begin{tabular}{|l|c|c|c|}
\hline \multicolumn{4}{|l|}{ Table 1. Laboratory investigations } \\
\hline Tests (Normal values) & Patient 1 & Patient 2 & Patient 3 \\
\hline LH $(<0.3 \mathrm{IU} / \mathrm{L})$ & 0.4 & $<0.1$ & - \\
\hline FSH $(<1.6 \mathrm{IU} / \mathrm{L})$ & 0.4 & $<0.1$ & - \\
\hline Testosterone $(<0.9 \mathrm{nmol} / \mathrm{L})$ & $\mathbf{5 . 6}$ & $\mathbf{1 0 . 2}$ & $\mathbf{3 . 6}$ \\
\hline $\begin{array}{l}\text { Androstenedione }(0.1-0.6 \\
\text { nmol/L) }\end{array}$ & 1.1 & $\mathbf{1 8 . 9}$ & - \\
\hline 17-OHP $(0-0.8 \mathrm{nmol} / \mathrm{L})$ & 0.7 & $\mathbf{4 . 3}$ & $\mathbf{2 . 1}$ \\
\hline $\begin{array}{l}\text { DHA-S }(0.7-5.7 \\
\text { micromol/L) }\end{array}$ & 1.1 & 1.8 & 4.5 \\
\hline AFP $(1-4 \mathrm{mcg} / \mathrm{L})$ & 2 & 3 & $\mathbf{4 . 5}$ \\
\hline$\beta-H C G(<2 \mathrm{IU} / \mathrm{L})$ & $<1$ & $<1$ & $<1$ \\
\hline LDH $(470-900 \mathrm{IU} / \mathrm{L})$ & 582 & 571 & $\mathbf{2 6 7}$ \\
\hline
\end{tabular}

AFP: alpha-fetoprotein: $\beta$-HCG: beta-human chorionic gonadotropin; DHA-S:

dehydroepiandrosterone sulphate; FSH: follicle-stimulating hormone; LDH: lactate dehydrogenase; LH: luteinizing hormone; 17-OHP: 17-hydroxyprogesterone. 